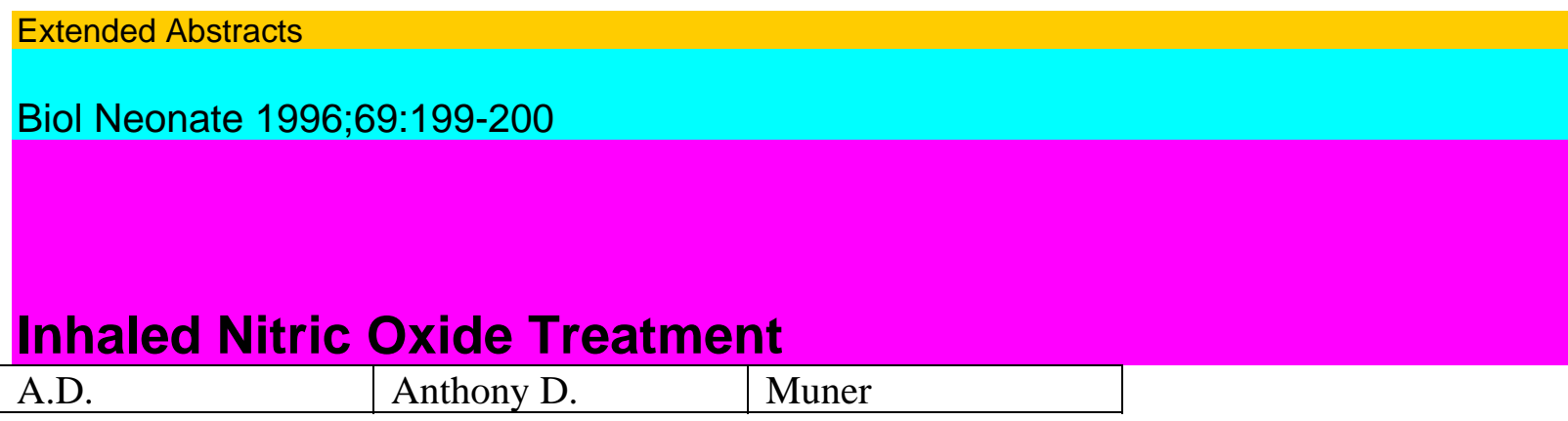

Department of Paediatrics and Neonatology, Guys and St. Thomas Hospital, London, UK

Prof. Anthony D. Milner, MD, Department of Paediatrics and Neonatology, St. Thomas Hospital, Lambeth Palace Road, London SE17EH (UK)

Persistent pulmonary hypertension of the newborn (PPHN) is a major cause of mortality and morbidity, causing a vicious cycle of increasing hypoxia and acidosis responding poorly to conventional ventilatory support. Its management has been revolutionised by the introduction of inhaled nitric oxide therapy [1]. Nitric oxide is derived from the conversion of arginine to citrulline by the enzyme nitric oxide synthase [2]. Although nitric oxide is important in maintaining vasodilata-tion in both the pulmonary and systemic circulation, it has been shown to have a very short half-life in vivo [3] and is then converted to nitrate and nitrite by oxygen and water. These can then react further with water to produce nitrous and nitric acids, but fortunately both react avidly with haemoglobin to produce small quantities of methaemoglobin [4]. The net effect of this is that nitric oxide administered to the airway will have its effect only on the pulmonary circulation avoiding the problems of severe systemic hypotension experienced with tolazoline and systemic prostacycline. There is now an increasing amount of literature on the use of nitric oxide in the treatment of PPHN [5-7], and although we do not yet have the results of any randomised controlled trials, physiological studies have shown that this therapy will often reduce pulmonary artery pressure [8], increase pulmonary blood flow and produce dramatic improvements in oxygenation with relatively low concentrations of nitric oxide ( $<20 \mathrm{ppm}$ ). Neonatally related conditions where success has been reported include idiopathic PPHN, and PPHN complicating meconium aspiration, diaphragmatic hernia [9], and respiratory tract infections in children with bronchoul-monary dysplasia [10].

There remains considerable interest in whether PPHN represents a failure of endogenous nitric oxide production. Our studies have shown that over the first $24 \mathrm{~h}$ of life, pulmonary artery pressure falls and effective pulmonary blood flow increases without any change in the expired nitric oxide concentration. After that there is a close inverse and direct relationship, respectively. There are also data indicating that infants with PPHN have lower urinary nitrite and nitrate levels [11], metabolites of nitric oxide and a study suggesting that infants developing PPHN

\title{
Extended Abstracts
}

BiolNeonate 1996;69:165-212

199

tend to have lower blood arginine concentrations than well-matched controls [12].

Anxieties about raised levels of methae-moglobin remain. There have been deaths from methaemoglobinaemia and some racial groups, e.g. Red Indians, have a tendency to low levels of 
methaemoglobin reductase. High levels have also been reported after the administration of high concentrations of nitric oxide ( $80 \mathrm{ppm})$ so that twice daily monitoring is recommended. The pollution effects of this therapy are also of increasing interest. A combination of potassium permanganate and activated charcoal provides a highly effective scavenging system, although charcoal alone, a much cheaper option, can be used. High frequency oscillators can lead to levels of nitric oxide in excess of $1 \mathrm{ppm}$ around the incubator and $>150 \mathrm{ppb}$ throughout the neonatal unit if scavenging systems are not used.

References

Moncada S, Palmer RMJ, Higgs EA: Nitric oxide: Physiology, pathophys-iology and pharmacology. Pharmacol Rev 1991:43:109-142. Moncada S, Palmer RMJ: The L-arginine:nitric oxide pathway in the vessel wall; in Moncada S, Higgs EA (eds): Nitric Oxide from L-Arginine: A Bioregulatory System. Amsterdam, Elsevier, pp 19-33. Vallance P, Collier J, Moncada S: Effects of endothelium derived nitric oxide on peripheral arteriolar tone in man. Lancet 1989;ii:997-1000.

Yoshida K, Kasama K, Kitabatake M, Okuda M, Imai M: Metabolic fate of nitric oxide. Int Arch Occup Environ Health 1980:46:71-77. Roberts JD, Polaner DM, Lang P, Zapol WM: Inhaled nitric oxide in persistent pulmonary hypertension of the newborn. Lancet 1992:340: 818-819. Kinsella JP, Neish SR. Shaffer E, Abman SH: Low dose inhalational nitric oxide in persistent pulmonary hypertension of the newborn. Lancet 1992;340:819-820. Kinsella JP, Neish SR. Shaffer E, Abman SH: Low-dose inhalation of nitric oxide in persistent pulmonary hypertension of the newborn. Lancet 1993;340:819-820. Roze JC, Storme L, Zupan V, Mor-ville P, DinhXuan AT, Mercier JC: Echocardiographíc investigation of inhaled nitric oxide in newborns with severe hypoxaemia. Lancet 1994;344:303-305.

9 Hcnneberg SW, Jepsen S, Andersen PK, Pedersen SA: Inhalation of nitric oxide as a treatment of pulmonary hypertension in congenital diaphragmatic hernia. J Pedíatr Surg 1995;30:853-855. Leclerc F, Riou Y, Martinot A. Storme L, Hue V, Flurin V, De-schildrc A, Sadik A: Inhaled nitric oxide for a severe respiratory syncy-tial virus infection in an infant with bronchopulmonary dysplasia. In-tensCareMed 1994;20:511-512.

Dollberg S, Warner BW, Myatt L: Urinary nitrite and nitrate concentrations in patients with idiopathic persistent pulmonary hypertension of the newborn and effect of extra-corporal membrane oxygenation. Pediatr Res 1995:37:31-34.

Vosatka RJ, Kashyap S, Trifiletti RR: Arginine deficiency accompanies persistent pulmonary hypertension of the newborn. Biol Neonate 1994:66:65-70.

200

Biol Neonate 1996:69:165-212

International Symposium on Recent Advances in Neonatal Medicine 